\title{
Responsabilidade corporativa da Jerónimo Martins: discurso que gera imagem empresarial positiva
}

\author{
Corporate responsibility of Jerónimo Martins: discourse that \\ generates positive business image
}

\author{
Dra. Marta Cardoso de Andrade, Universidade do Sul e Sudeste do Pará (UNIFESSPA) \\ dramartaandrade@gmail.com | https://orcid.org/0000-0003-4461-8139 \\ Folha 31, Quadra 07, Lote Especial, s/n (Nova Marabá) Marabá (PA)-Brasil
}

\begin{abstract}
Resumo
Este artigo visa estudar a imagem empresarial construída discursivamente a partir da apresentação das ações de Responsabilidade Corporativa $(R C)$ de um dos maiores grupos portugueses, a empresa multinacional, o Jerónimo Martins. A RC se constitui componente importante para a perpetuação dos negócios implementados nas organizações atualmente, como igualmente na valorização do capital reputacional. Para tanto, estudou-se o ethos organizacional (formado a partir das escolhas lexicais, como também via escolha dos argumentos disposto nas produções textuais selecionadas), uma vez que esse elemento retórico termina por representar a estruturação da imagem corporativa num discurso. Desta forma, buscou-se a explicitação desse elemento nos textos publicados no primeiro capítulo de um documento da Comunicação Dirigida (CD) existente no referido Grupo, a saber: o Relatório de Responsabilidade Corporativa 2016. Visando a realização deste trabalho, foi utilizado como aporte teórico os pressupostos da citada Responsabilidade, da Comunicação Organizacional (com foco na CD) e da Análise do Discurso de linha francesa, sendo que esta última também se constitui a metodologia seguida para a feitura da pesquisa. Para se empreender este estudo, foram realizados dois tipos de análises: a dos dados linguísticos e a dos argumentos usados nas produções textuais examinadas. Como resultado, obteve-se a mencionada imagem, bem como se observou que essa se edificou de forma positiva através da construção do ethos oriundo do discurso da RC.
\end{abstract}

\begin{abstract}
This article aims to study the corporate image constructed discursively from the presentation of the Corporate Responsibility (CR) actions of one of the largest Portuguese groups, the multinational company, Jerónimo Martins. The CR is an important component for the perpetuation of the
\end{abstract}

Forma de citar:

Cardoso, M. (2019). Responsabilidade corporativa da Jerónimo Martins: discurso que gera imagem empresarial positiva.

Ámbitos. Revista Internacional de Comunicación, 44, 93-109. doi: 10.12795/Ambitos.2019.i44.06 
businesses implemented in the organizations today, as well as for the valorization of reputational capital. For this, the organizational ethos (formed from the lexical choices, as well as the choice of the arguments in the selected textual productions) was studied, since this rhetorical element ends up representing the structuring of the corporate image in a discourse. In this way, this element was explicated in the texts published in the first chapter of a document of the Directed Communication (DC) existing in said Group, namely: Relatório de Responsabilidade Corporativa 2016. In order to carry out this work, it was used as contribution theoretical aspects of the aforementioned Responsibility, the Organizational Communication (with focus on the DC) and the Discourse Analysis of the French line, the latter also constituting the methodology used to carry out the research. In order to undertake this study, two types of analysis were carried out: the linguistic data and the arguments used in the textual productions examined. As a result, the aforementioned image was obtained, and it was observed that it was positively built through the construction of the ethos that came from the CR discourse.

Palavras-chave: análise do Discurso, Responsabilidade Corporativa, Imagem Empresarial, Ethos, Relatório.

Keywords: discourse Analysis, Corporate Responsibility, Corporate Image, Ethos, Report.

\section{INTRODUÇÃO}

A forma de fazer negócios está mudando, sendo, atualmente, resultado da percepção de fatores econômicos, sociais e políticos. Dessa maneira, tem-se de observar que a democratização e a diminuição do papel do Estado; a crescente conscientização dos stakeholders ${ }^{1}$ acerca dos impactos sociais e ambientais das ações corporativas; o poder das mídias sociais em alterar a natureza do debate e a forma de se pensar e refletir acerca de algumas questões; o papel cada vez maior de terceiros em influenciar o comportamento de investidores, consumidores e até outros públicos de interesse organizacional, são alguns importantes aspectos, os quais desencadearam uma alteração significativa nas expectativas sociais sobre a responsabilidade das organizações².

Destaca-se, assim, que a relação das empresas com a sociedade e com outros públicos de interesse tem se modificado no sentido de envolver maior transparência e a prestação de contas sobre temas e os atores que não eram importantes no processo de legitimação social anteriormente (Oliveira, 2005). Entre os temas de maior destaque neste tocante estão: a governança corporativa, o tratamento ao público interno, as questões sociais e as de preservação do meio ambiente, relações com comunidades, entre outros. Enquanto que os stakeholders relevantes já incluem empregados, investidores, comunidades, clientes, governos e organizações não-governamentais, os quais antes não eram tão relevantes.

Em meio a esse panorama, nas últimas décadas, Travassos (2012, p. 10) afirma que

(...) a Responsabilidade Corporativa [RC] disseminou-se como ideologia e prática gerencial no mundo empresarial e aparece como um tema recente, mas de crescente interesse 
na mídia, empresariado, academia, governo e sociedade civil em todo o mundo. O tema é tratado por diferentes termos análogos, tais como responsabilidade social corporativa, sustentabilidade, cidadania corporativa e ética empresarial.

Ao se partir dessas ponderações e da necessidade de se analisar textos/discursos sobre a RC presentes no cotidiano das organizações, principalmente aquelas de capital aberto, escolheu-se trabalhar com o Relatório de Responsabilidade Corporativa 2016 de uma instituição multinacional, originária do mercado português, o Grupo Jerónimo Martins ${ }^{3}$, sendo esse documento pertencente à Comunicação Dirigida (CD) e produzido inicialmente para os investidores e os acionistas, mas que termina por alcançar cada vez mais um número maior de stakeholders, interessados em questões referentes à RC.

Para a realização deste artigo, foi utilizado como aporte teórico os pressupostos da Responsabilidade Corporativa, ou seja, os da Sustentabilidade Empresarial (SE); da Comunicação Organizacional (CO) (especificamente os da Comunicação Dirigida); e da Análise do Discurso (AD) de linha francesa. Esta última constituiu-se igualmente a metodologia empreendida para a feitura deste estudo.

Ao objetivar a feitura deste trabalho, teve-se de escolher um dos capítulos do referido Relatório, mais especificamente o primeiro, intitulado de $A$ nossa abordagem. Isso se deu porque a pesquisadora desenvolveu uma metodologia, em seu doutoramento, a partir da $A D$, a qual está focada na construção discursiva embasada nas escolhas dos itens linguísticas e dos argumentos expressos na materialidade do discurso examinado, e não há como, a partir dessa, analisar todo o documento escolhido. Dessa maneira, justifica-se a escolha metodológica de exame de apenas essa parte do relato a ser estudado.

Observa-se que este documento é detentor, a seguir, de uma pequena base teórica acerca dos principais tópicos que foram abordados na análise realizada, a qual aparece logo após a explicitação do texto estudado, por fim, são levantadas as considerações finais obtidas com a feitura deste estudo.

\section{CAMINHO TEÓRICO SEGUIDO}

Planejar e gerir os negócios de maneira responsável, segundo Duarte (2008), é instituir um compromisso de longo prazo com os princípios de comprometimento com os aspectos sociais e com a integridade e preservação do meio ambiente. Esse pacto, que as corporações realizam com o futuro da planeta e dos seres humanos que nele habitam e com os que ainda habitarão, é medido por meio de suas iniciativas, as quais levam em conta o uso comprometido e comedido dos recursos necessários a sua atuação empresarial, sejam esses humanos, econômicos, sociais ou ambientais, visando os desenvolvimento das ações dessas organizações.

Ainda de acordo com essa visão hodierna, um comportamento organizacional como esse se reverte em diferencial de longo prazo para as companhias, pois imputa vantagem competitiva, 
construção de imagem positiva e aumento de capital reputacional. Dantas (2009, pp. 86-87) adverte que a estratégia de Responsabilidade Corporativa deve

(...) basear-se no desenvolvimento de um vasto conjunto de práticas e processos, apoiados em três vertentes, que consideramos como de grande importância para as organizações a econômica, a ambiental e a social (...).

Félix (2009, p. 12) confirma a posição de Dantas ao defender que "(...) o tripé da sustentabilidade chega, assim, para orientar as tomadas de decisão do primeiro, segundo e terceiro setores ${ }^{[4]}(\ldots)$ ", sendo aquele formado pelos recursos ambientais, os sociais e os econômico-financeiros das corporações, como já mencionado. Dessa forma, percebe-se que as responsabilidades social e ambiental podem ser consideradas pilares da sustentabilidade nos negócios (Sardinha, 2009), isto é, o sustentáculo, ao lado do pilar financeiro, da dita Responsabilidade Corporativa.

Cabe então entender o que vem a ser o termo "responsabilidade corporativa", o qual possui diversas denominações, como já asseverado, e vários significados.

Como destaca Travassos (2012, p. 17), "Mesmo com a relevância crescente da responsabilidade corporativa no ambiente empresarial, não existe uma definição consensual do que uma empresa deve fazer para ser socialmente responsável". Sob o ponto de vista de Oliveira (2005), no geral, a RC está relacionada a uma gestão empresarial mais transparente e ética, bem como à inserção de preocupações sociais e ambientais nas decisões e resultados das empresas.

Para efeitos da proposta de estudo apresentada neste documento, será a RC entendida como

(...) prover o melhor para as pessoas e para o ambiente no presente e com vista ao futuro. Assim, a sustentabilidade está ligada a uma visão de longo prazo e se constitui em fator de motivação para a organização que consegue conduzir suas ações de forma ética.

A empresa precisa contribuir com o desenvolvimento da sociedade, monitorando os impactos econômicos, sociais e ambientais de suas ações em relação às diversas partes interessadas. A preocupação com seus stakeholders é primordial para as operações sustentáveis de uma organização (Neves, 2009, p. 202).

Essa preocupação com os públicos de interesse e com a ética termina por gerar "(...) melhorias da qualidade de vida e um novo modo de pensar o bem-estar humano" (Sardinha, 2009, p. 45), as quais são consequências naturais da Responsabilidade Social Empresarial (RSE) (igualmente sinônima da RC). Assim, Sardinha (2009, p. 45) afirma que

A adoção de práticas de RSE, mesmo que a empresa não obtenha ganhos econômicos, faz a empresa obter aumento do seu capital reputacional, afirma Zilberstajn (2000 apud Daher et al., 2006), que enfatiza também que esse efeito se dará sem que haja um desarranjo entre os interesses dos acionistas e das outras partes interessadas. Assim, fica evidente 
que a responsabilidade social das empresas deve considerar todos os atores ou todas as pessoas que estão ou são interessadas em suas decisões e ações.

Assim, cabe entender o que vem a ser conceitos basilares para esta pesquisa, a saber: capital reputacional, imagem, identidade e reputação corporativas, os quais são importantes igualmente para que se entenda o trabalho que envolve a SE praticada pelas organizações, dentre essas a Jerónimo Martins, estudada neste documento.

Sobre a compreensão do que seja o capital reputacional, inicialmente, cabe saber o que constitui a "Reputação Corporativa", a qual é uma expressão usada e advinda da área das Relações Públicas, mas especificamente centrada na teoria da Comunicação Organizacional. Segundo Blamer e Greyser (citado em Almeida, 2006, p. 232), a reputação "(...) é construída ao longo dos anos e tem como base as ações e os comportamentos da empresa". Almeida (2006, p. 232) advoga que esse conceito possui uma dimensão histórica, a qual termina por refletir a percepção da consistência da ação, da postura e do comportamento da corporação no decorrer do tempo. Isso porque representa um julgamento de valor que o(s) público(s) imputa(m) sobre as qualidades e defeitos empresariais que são construídas no decorrer de um período relativamente extenso, ou seja, é constituída a partir da cristalização das várias imagens corporativas na linha do tempo. Dessa forma, quanto mais positiva for a reputação, maior será, portanto, o valor daquele capital.

Compreendido isso, segundo Machado Filho e Zylbersztajn (2004), capital reputacional pode ser compreendido como sendo aquela porção do valor de mercado da empresa que pode ser atribuída à percepção que se tem da firma como uma corporação de boa conduta no mercado. Ainda para Machado Filho (2002, p. 63), “(...) é formado por várias dimensões que moldam a imagem de uma determinada corporação”.

Ao se pensar sobre a imagem corporativa, pode-se afirmar que essa é a percepção que se tem da organização e é oriunda das informações recebidas acerca dessa empresa. Partindo-se do raciocínio de Villafañe (1998, p. 30), o conceito de imagem empresarial versa sobre "(...) o resultado interativo que um amplo conjunto de comportamentos da organização produzem no espírito dos seus públicos", enquanto que para Ruão (2006, p. 89) "(...) é uma representação mental que um indivíduo faz de uma organização, como reflexo da sua cultura, práticas e comunicação". Em outro trabalho, Ruão (2003, p. 17) ainda define a imagem corporativa como sendo uma

(...) impressão criada ou estimulada por um conjunto de signos, resultantes da totalidade das formas de comunicação entre a empresa e os seus públicos, sendo essencialmente, um processo de representação contínuo e de reciprocidade, composto pelas percepções de membros e não membros da organização.

Enquanto que a identidade empresarial “(...) é definida como o conjunto de princípios e valores dos gestores e funcionários da empresa (...) aparece na forma das práticas administrativas empregadas nas relações internas e externas da empresa" (Machado Filho, 2002, p. 66), ou 
seja, é o que a organização é, sendo a partir dessa que se realizam, elaboram e concretizam as imagens e a reputação corporativa.

"A empresa é reconhecida pelo seu nome [identidade] e pelas suas apresentações, formando imagens mentais que levam à formação da reputação corporativa (...)" (Machado Filho, 2002, p. 66), a qual se constitui ao longo do tempo. A figura 1 termina por demonstrar a relação entre esses três conceitos.

Figura 1. Interrelação entre Identidade, Imagem e Reputação Corporativa Fonte: Adaptado de Fombrun (1996) por Machado Filho (2002).

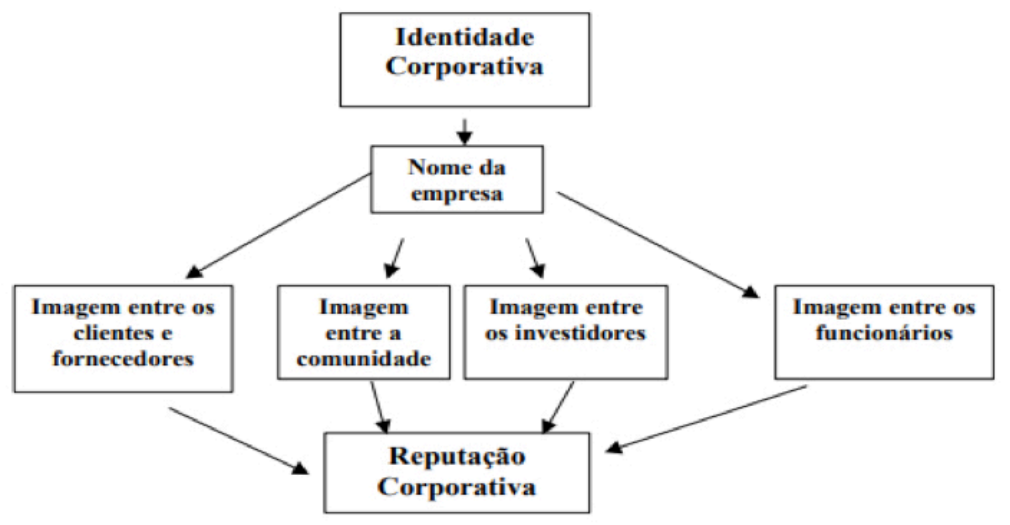

Sabe-se que, neste artigo, estudar-se-á como o discurso acerca da Responsabilidade Corporativa (focando-se na construção da imagem e, consequentemente, no capital reputacional) é construído na parte que versa sobre esse assunto e foi publicado no Relatório de Responsabilidade Corporativa ${ }^{5} 2016$ da Jerónimo Martins. Esse documento, de uma forma geral e no casso da organização estudada, visa comunicar os atos de responsabilidade empresarial e se transformou no principal instrumento de comunicação dirigida com essa finalidade. Na visão defendida por Duarte (2008, p. 85), esse relatório é

Resultado de um conjunto de dados e de indicadores dos investimentos, além das iniciativas de cunho social direcionadas aos diversos públicos com os quais a empresa interage, esses relatórios cumprem a função de conferir transparência e dar visibilidade desses feitos, levando informações não apenas aos acionistas das companhias (shareholders, no jargão do mercado), mas também a um número maior de públicos estratégicos (stakeholders) (...).

Ao se visar a realização da investigação proposta neste trabalho, utilizar-se-á ainda o aporte teórico da Análise do Discurso (AD) de linha francesa, a qual terá dupla função neste estudo, como já mencionado: a de se constituir como uma teoria e a instituir o percurso metodológico a ser seguido na análise dos dados coletados. Ao se objetivar entender as bases teóricas desse campo do saber utilizadas na feitura deste artigo, iniciar-se-á com alguns conceitos usados por aquela, mas oriundos da Retórica de Aristóteles. 
Sob o ponto de vista de Meyer, Carrilho e Timmermans (2002, p. 50), a maior inovação impressa por aquele pensador grego retórico está na "(...) sistematicidade através da qual ele integra três elementos fundamentais do discurso (...)": o ethos - indicando quem fala (ou escreve) -, o logos - o qual constitui argumento apresentado - e o pathos - a quem se dirige, aquele que ouve ou lê (Figura 2).

Figura 2. Articulação entre os três componentes da persuasão Fonte: Adam (2005, p. 93)

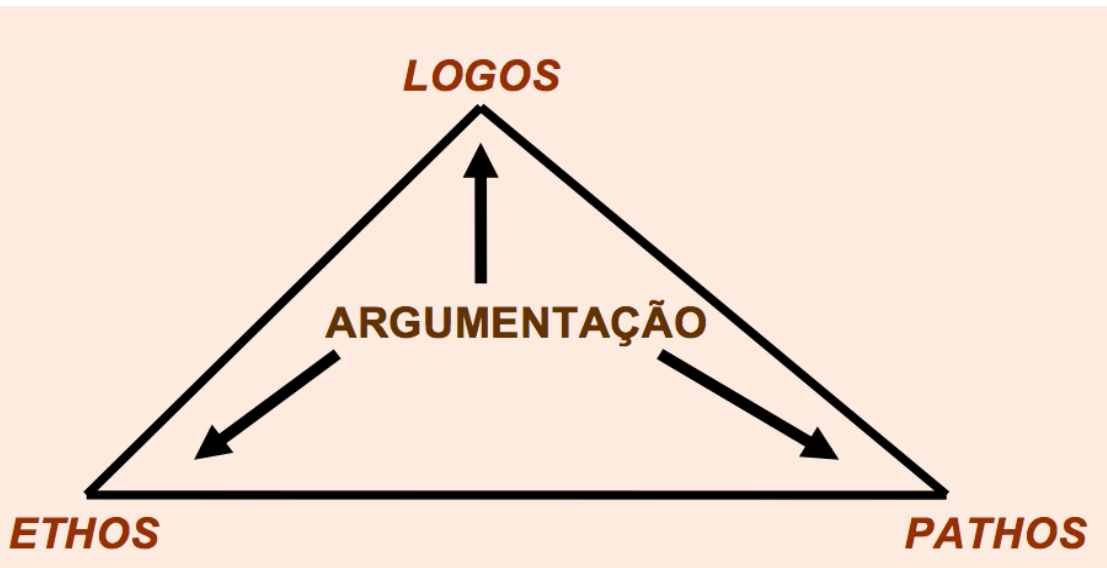

Aristóteles ([V a.C.] 1998) igualmente defendeu que a persuasão fornecida pelo discurso pode ser de três espécies, mas se deterá a atenção, neste documento, apenas no primeiro desses casos, ou seja, naquele que reside no caráter moral do orador, ou seja, no centrado no ethos. Para se conseguir persuadir pelo caráter, o discurso (logos) deve ser montado e proferido/escrito de tal forma a passar a impressão de que o orador é digno de fazê-lo. Aquele filósofo grego acreditava que o ser humano está sempre mais propenso a crer com maior firmeza/convicção e de forma mais rápida em indivíduos tidos como de bem e honestos - hoje, esses podem também ser organizações, ou a "voz" identificadoras dessas - ou seja, um dos segredos da persuasão está no orador/escritor ${ }^{6}$ passar e construir uma imagem favorável de si mesmo, imagem essa que deve seduzir o auditório (pathos), bem como captar a benevolência e a simpatia deste. Esta representação do orador é o que constitui o ethos, o qual equivale ao caráter que o orador (ser real) atribui a si mesmo pelo modo como exerce sua atividade retórica. Trata-se da aparência que Ihe confere a fluência, outrossim, a escolha das palavras e dos argumentos. O ethos funcionaria como um elemento que reforçaria a plausibilidade da argumentação exposta, o que, não se deve tanto aos aspectos morais do orador, mas àquilo que é resultado do próprio discurso, o que é vital, neste tocante, é que a confiança imputada no orador seja um "efeito" do discurso deste. 
Como já demonstrado, a argumentação também termina por auxiliar na construção desse ethos. Para Philippe Breton (1999, p. 26), "(...) argumentar é raciocinar, propor uma opinião aos outros dando-Ihes boas razões para aderir a ela". Dessa forma, o orador pode usar mais esse elemento para ajudá-lo no seu intento persuasivo e na construção discursiva/textual.

Para empreender a análise proposta neste trabalho, ainda há alguns conceitos da AD os quais devem ser apresentados para que melhor se abarque um discurso/texto.

Assim, em primeiro lugar, urge entender o que vem a ser o discurso. Segundo Orlandi (2002, p. 21), esse pode ser entendido como sendo "(...) efeitos de sentido entre locutores", sabendo-se que esse "(...) tem sua regularidade, tem seu funcionamento que é possível apreender se não opomos o social e o histórico, o sistema e a realização, o subjetivo ao objetivo, o processo ao produto" (p. 22). Todo discurso tem condições de produção específicas e essas são denominadas de enunciações e determinam a elocução de um discurso e não de outros, uma vez que se referem a "(...) determinadas circunstâncias, a saber, o contexto histórico-ideológico e as representações que o sujeito, a partir da posição que ocupa ao enunciar, faz de seu interlocutor, de si mesmo, do próprio discurso etc." (Mussalim, 2001, p. 116).

Urge igualmente entender quem são os responsáveis pela produção e recepção desses discursos. Num dado discurso, acerca das personagens as quais se reportam ao orador, usando-se a visão de Ducrot (1987, p. 193), podem-se identificar três entidades, as quais são: o "sujeito falante" ou "autor empírico do enunciado" (produtor exterior ao sentido do enunciado), o "locutor" ("ser que, no próprio sentido do enunciado, é apresentado como seu responsável", equivalendo ao "ser de discurso") e há ainda o "enunciador" (ser de pura enunciação, que determina o ponto de vista a partir do qual os acontecimentos são apresentados, podendo ser denominado de "sujeito da enunciação", ou seja, é um efeito do enunciado).

Ao se contrapor às figuras produtoras do discurso, existem aquelas que respondem pela recepção desse, são as seguintes: "co-enunciador" (correlativo de enunciador, uma vez que a enunciação é igualmente uma co-enunciação, na qual dois indivíduos desempenham papéis ativos), "alocutário" (refere-se ao que poderia denominar de "destinatário direto" do discurso, a eles o locutor atribui um "lugar" enunciativo) e "leitor" (seria um co-enunciador virtual, uma vez que o diálogo deste com o "escritor"/sujeito falante é mais da ordem informativa do que da ordem do linguísticocomunicativo). Este último ainda pode ser considerado a partir de dois ângulos diferentes: (1) como o público efetivo de um texto, ou (2) como o público que esse texto implica por suas características, ou seja, os traços textuais permitem reconstruir uma representação que o "escritor" teve de criar daqueles que iriam ler o seu texto.

No caso de haver esses atores discursivos, existirá a subjetividade enunciativa. Benveniste (1995, p. 286) afirma que essa "(...) é a capacidade (...) [de] se propor como "sujeito" e identifica as formas disponibilizadas pela língua para essa finalidade: o pronome "eu", que é a própria consciência de si mesmo; o pronome "tu", que advém do contraste com o "eu" (esses dois constituem a denominada "intersubjetividade"); as formas temporais; como também as indicadoras da dêixis e 
os verbos modalizadores conjugados na primeira pessoa. Dessa maneira, apresenta-se assim a denominada embreagem textual. Esses elementos terminam por auxiliar na formação da situação de enunciação, sendo apresentados comumente pelo "EU" e "TU" - embreagem de pessoa - pelo "AGORA" - embreagem de tempo -, e pelo "AQUI" - embreagem de espaço.

Ao ampliar esse inventário de marcadores de subjetividade preconizado por Benveniste (1995), Kerbrat-Orecchioni (1993) acrescenta os modalizadores/caracterizadores/adjetivos - os quais são formas indicadoras da atitude do sujeito falante frente a seu interlocutor, a si mesmo e o seu próprio enunciado. Essa teórica propôs uma classificação que dividiu os adjetivos em: "objetivos", aqueles que visam apenas descrever; e "subjetivos", os quais são as formas indicadoras da subjetividade enunciativa.

Quando se pensa sobre a questão do tempo, Benveniste também apresentou a ideia de "tempo linguístico", cuja singularidade está

(...) organicamente ligado ao exercício da fala, o fato de se definir e de se organizar como função do discurso (...) Cada vez que um locutor emprega a forma gramatical do "presente" (...), ele situa o acontecimento como contemporâneo da instância do discurso que o menciona (Benveniste, 1989, pp. 75-76).

Com vista da ampliação desse conceito acerca da embreagem temporal, Fiorin (2002) assevera que todo discurso instaura um "agora", o qual equivaleria ao momento da enunciação, que transcorre no tempo presente linguístico, no qual há uma "concomitância" entre o acontecimento narrado e o momento da narração e há aqueles em que ocorre a "não-concomitância", que se subdivide em "anterioridade" e "posterioridade" ao momento "agora". A temporalidade instaurada pela língua se refere também às relações de sucessividade entre estados e transformações representados na própria produção textual. Dessa forma, como ainda chama atenção Fiorin (p. 146), nota-se que há na língua dois sistemas temporais, mas, para efeitos deste trabalho, só se observará o enunciativo, que está "(...) relacionado diretamente ao momento da enunciação (...)", organizado a partir do presente que está implícito ou explícito na enunciação. Assim, se percebe que, quando o momento de referência (MR) e o de enunciação (ME) são coincidentes, usa-se este sistema.

Ao se chegar ao fim deste breve percurso teórico, deve-se lembrar que o objetivo principal deste trabalho é observar se construção do ethos (esse conduz discursivamente a construção da imagem corporativa) e da situação enunciativa auxiliam na elaboração do discurso persuasivo em um texto sobre a RC publicado num Relatório de uma grande corporação portuguesa e europeia, no caso o Grupo Jerónimo Martins.

Feitas essas breves considerações introdutórias referentes à teoria que embasou a investigação a seguir, passa-se na sequência à explicitação/detalhamento dos textos escolhidos e, logo depois, para a análise propriamente dita. 


\section{O TEXTO A SER ANALISADO}

Para a realização deste artigo, como já foi mencionado, foi selecionado apenas um dos capítulos do Relatório de Responsabilidade Corporativa 2016 (2016) do Grupo Jerónimo Martins, mais especificamente o primeiro, denominado de A nossa abordagem ${ }^{7}$.

Nesta parte do referido documento, há um total de cinco textos, divididos, dessa forma, para efeitos de análise deste trabalho, mas que se contados de forma padrão (título e corpo textual) seriam quatro. Assim, por escolha metodológica, esta pesquisadora os segmentou da seguinte forma: um que apresenta o capítulo e está situado logo abaixo do título do próprio capítulo; outro que versa sobre as estratégias de RC adotadas pelo Grupo estudado; na sequência, encontrase o denominado de Modelo de Negócio e Relação com o Desenvolvimento Sustentável, texto apresentado a partir de uma figura que explicita o citado modelo; ao lado, acha-se a produção textual intitulada de Grupo Jerónimo Martins incluído nos índices FTSE Russel; e, por último, há o Combate ao desperdício alimentar.

Passa-se, a partir da próxima seção, a análise empreendida nessas produções para se chegar a construção discursiva e do ethos, o qual implicam na imagem corporativa do referido Grupo.

\section{ANÁLISE PROPRIAMENTE DITA}

Esta análise busca identificar, discursivamente, qual a imagem corporativa percebida ao se ler as produções do capítulo 1 do Relatório de Responsabilidade Corporativa 2016 da Jerónimo Martins.

Como já afirmado por Andrade (2018, p. 12), o primeiro aspecto a ser destacado é que esse capítulo termina por constituir a "voz" da organização em questão e isso fica evidente no título dessa parte, no único item linguístico indicador da primeira pessoa encontrado em toda essa divisão: o "nossa", o qual é um pronome possessivo, que igualmente aponta para algo inerente ao enunciador discursivo, mas também ao locutor e ao sujeito falante. O motivo desse item ser apenas um para explicitar a voz identificadora da organização estudada, em todo o capítulo examinado, está na tentativa de se expressar um distanciamento enunciativo, conduzindo a uma pseudoneutralidade, uma vez que os fatos serão apresentados sem a presença do enunciador no texto, contudo, é expressivo uma vez que o ethos organizacional se faz presente em toda a sua força apresentando um EU amplificado a partir da $1^{\mathrm{a}}$. pessoa do plural.

Ainda seguindo essa linha de análise dos itens linguísticos, buscou-se investigar os embreantes textuais.

Nos cinco textos selecionados, observa-se a presença de 8 expressões indicadoras de tempo propriamente ditas, ou seja, os advérbios com essa finalidade, entretanto, se sabe, como foi mencionado antes, que os tempos verbais também auxiliam neste tipo de embreagem (Fiorin, 2002, pp. 142-171). Assim, nesta produção, encontram-se, em totalidade, tempos relacionados ao sistema enunciativo e, em maioria quase absoluta, no tempo presente, são 20 ocorrências dos verbos plenos (aqueles que marcam o tempo em presente, passado e futuro, isto é, os dos modos 
indicativo ou subjuntivo) e 35 dos semiplenos (aqueles que não marcam tempo, ou seja, as formas nominais do verbo: infinitivo, gerúndio e particípio; esses só expressam aspecto quando ligados aos tempos plenos que terminam por Ihes determinar a ancoragem temporal). Esse sistema cria, para o co-enunciador e leitor a impressão de que também faz parte do momento da enunciação. Há verbos no tempo pretérito (plenos são 5 e semiplenos 6), os que marcam a posterioridade aos fatos do presente, os quais terminam por auxiliar o enunciador na narrativa cronológica de algum fato para que o co-enunciador e leitor/ouvinte melhor entenda os ocorridos no presente.

Igualmente cabe destacar que, na produção textual sobre as estratégias de RC adotadas pela empresa investigada, encontra-se a explicitação dessas e, para tal intento, cada uma dessas é explicitadas com verbos semiplenos. Essa é uma estratégia importante disponibilizada pela língua portuguesa: quando os verbos não apresentam aspecto, denotam atemporalidade e, consequentemente, uma convicção de algo vivenciado constantemente nas organizações e com a estudada não ocorreria de maneira diferente.

Cabe destacar, quanto aos embreantes de lugar, que há 4 explícitos, todos encontrados no texto intitulado de Grupo Jerónimo Martins incluído nos índices FTSE Russel. Andrade (2018, p. 13) a firma que a função desses é ancorar o texto entre as dependências do referido Grupo, nos índices que lhes são externos e no mercado de atuação da organização pesquisada, isto é, uma ancoragem de local bastante extensa. Todavia, ainda cabe destacar que, de forma interpretativa, por conhecimento de mundo e partilhado entre sujeito falante e leitor/ouvinte, sabe-se que o verbalizado, nos demais textos, acontece nas dependências de funcionamento do Grupo Jerónimo Martins.

Enquanto sobre as marcas explícitas da presença do "EU" e do "TU", a mesma pesquisadora (2018, p. 13) nota que essas sofreram quase total apagamento, como já citado, existe apenas uma no título do capítulo (o pronome possessivo "nossa"). Esse apagamento produz um efeito de sentido de distanciamento do enunciador organizacional e os fatos passam a ser apresentados pelo locutor em sua narração acerca do ocorrido, fazendo com que o alocutário e leitor aceitem mais facilmente o exposto, uma vez que não há subjetividade presente nesse.

Acerca da utilização dos adjetivos e locuções adjetivas, os quais também marcam a presença enunciativa ou a ausência dessa, percebe-se, pelo próprio foco discursivo da produção textual analisada, que há uma predominância total dos caracterizadores objetivos: são 106 ocorrências para os adjetivos e 71, para as locuções adjetivas. Isso acontece quando se quer apagar a subjetividade enunciativa em prol de uma voz organizacional neutra, a qual não deve possuir explicitamente subjetividade ou impessoalizar o enunciador, que, no caso, é a própria Jerónimo Martins. Contudo, há a presença de 6 adjetivos subjetivos, que indicam uma relativa subjetividade enunciativa de quem está escrevendo a produção textual em questão, no caso os profissionais da referida corporação que escreveram o texto analisado, instaurando a presença da "voz" enunciativa da organização. 
Sobre a análise empreendida a partir dos argumentos encontrados nos textos investigados, foi feita por produção textual, como igualmente realizado por Andrade (2018, pp. 13-14), individualizandoas a partir da sua composição argumental. No primeiro texto, observa-se a presença do argumento de superação, o qual consiste "(...) na possibilidade de ir sempre mais longe num sentido, sem que entreveja um limite nessa direção, e isso com um crescimento contínuo de valor" (Perelman \& Olbrechts-Tyteca, 2002, p. 327). A produção em questão explicita que a organização estudada trabalha de forma sustentável, o que já é uma superação para uma corporação do seu porte, bem como procura mitigar os impactos de umas atividades, fato igualmente que expõe a sobrepujança da Jerónimo Martins.

A estratégia de RC do Grupo estudado, encontrada no segundo texto, foi dividida em cinco pilares/objetivos, que são expostos igualmente em argumentos superação, uma vez que a empresa terá que os alcançar, superando-se. Isso é ratificado com as escolhas lexicais dos verbos em atemporalidade, típicas de verbalização de objetivos. Enquanto que para explicar cada um desse, foram escolhidos argumentos de definição, sabendo-se que esses pertencem ao "(...) campo das escolhas possíveis" (Breton, 1999, p. 96). Breton (p. 97) afirma que definir "(...) é um elemento chave de reenquadramento do real, que implica em uma certa criação, ao menos em uma escolha entre situações possíveis (...)". A Jerónimo Martins escolhe quais são os eixos norteadores de sua estratégia e os define dentre as possibilidades que existem para essa conceituação. O mesmo acontece com o terceiro texto em que há argumentos de definição acerca do que seria a compreensão dessa organização sobre o seu modelo de negócio e como essa entende a sua relação com o Desenvolvimento Sustentável. A diferença entre a segunda e a terceira produções investigadas está na sua forma de apresentação: enquanto que aquela é constituída toda em linguagem verbal, esta utiliza-se da linguagem com ilustrações, ou seja, é composta pela linguagem não-verbal, mas sua força está na exposição em figura e fotografias, o que facilita a compreensão do exposto por parte do co-enunciador, bem como torna o documento mais atrativo em termos gráficos.

Ao se partir para o quarto texto, é encontrado, de forma geral, o argumento de competência, o qual “(...) supõe que haja previamente uma competência científica, técnica, moral ou profissional que vai legitimar o olhar sobre o real que deriva dela" (Breton, 1995, p. 80). No caso, a competência advém FTSE Russell, que ranqueia as organizações a partir de seus índices e a Jerónimo Martins, como verbaliza o texto analisado, foi incorporada a esses. De forma específica, ainda se tem dois parágrafos de argumentos de superação: no primeiro, que apresenta a superação da empresa na questão da RC, a qual conduziu a sua visibilidade por parte de importantes stakeholders; e, no último, em que se expõe esse ultrapassar de limites do Grupo estudado, uma vez que está melhorando o seu desempenho a ponto da FTSE incluí-lo nos seus índices: FTSE4 Good Global Index e FTSE4 Good Europe Index. Também se encontra o argumento de definição ao se explicitar em que consiste os referidos índices.

Por fim, o último dos textos, é montado por argumentos de superação e definição: estes aparecem na apresentação dos cinco pilares da estratégia da Jerónimo Martins, algo bem similar ao presenciado no segundo texto; enquanto aqueles estão no restante a produção. 
Pela enunciação das produções encontradas no capítulo selecionado para este estudo, observase que os textos analisados "encarnam" as propriedades associadas comumente aos gestores com preocupações em relação à formação de uma imagem positiva da empresa que administram junto aos seus públicos de interesse, mais especificamente os investidores e os acionista, sem descartar o alcance de outros stakeholders, o que se vem comprovando cada vez mais com a publicitação de Relatórios de cunho de Responsabilidade Corporativa como o examinado neste trabalho, uma vez que há cada vez mais pessoas que se preocupam com a atuação organizacional em nível social e ambiental, pois em nível econômico a própria empresa já se encube de deter sua atenção, já que esse determina a sobrevivência desta.

Com esse intuito, no capítulo publicado no Relatório de Responsabilidade Corporativa 2016 da Jerónimo Martins e analisado neste artigo, o ethos construído é de uma corporação que se preocupa com o impacto de suas ações junto à sociedade e ao meio ambiente, bem como tenta superar-se no decorrer da linha do tempo, tendo consciência de suas responsabilidades enquanto entidade jurídica que se relaciona com os seus públicos de interesse, os quais buscam constantemente informações consistentes acerca da atuação organizacional no tocante a sustentabilidade.

\section{CONCLUSÕES}

Pode-se afirmar, a partir do estudo realizado, que o discurso apresentado pela organização em questão apresenta a construção de um ethos corporativo, o qual "encarna" a preocupação hodierna circulante na sociedade, nos shareholders (público destinatário precípuo do tipo de produção textual analisada neste documento) e nos stakeholders em torno da dita Responsabilidade Corporativa, ou melhor, da Sustentabilidade Empresarial. Debruçar-se e atuar de maneira sustentável conduz a uma formação de imagem positiva da organização, o que é objeto de desejo de toda companhia.

Portanto, o que foi percebido com esta pesquisa é que o ethos do Grupo Jerónimo Martins é o de uma empresa com ações e atuação voltadas para sua sustentabilidade empresarial e a da sociedade na qual está inserida igualmente. SE essa oriundas da teoria produzida para esse campo do saber ou da dinâmica inerente ao próprio mercado no qual essas instituições estão localizadas, o qual tem como principal foco é a formação de uma imagem corporativa positiva, que é formada discursivamente a partir da construção do ethos encarnado pela organização. Para se construir essa percepção imagética, pode-se asseverar que esse elemento retórico foi montado de forma preponderante para persuadir o co-enunciador e o leitor do discurso acerca da RC do referido Grupo português, no caso os investidores e acionistas, os quais se destinam precipuamente, como já mencionado, os Relatórios destinados a verbalização das ações de Responsabilidade Corporativa, mas que esses documentos atingem cada vez mais um número maior de stakeholders, sendo elaborado a partir tanto das escolhas linguísticas quanto das argumentativas. Também se pode defender que esses documentos de comunicação dirigida ganham cada vez mais prestígio e graus de dificuldade em sua feitura, seguindo uma 
normatização cada vez mais detalhada e "engessada" para todas as empresas que estão listadas nas bolsas de valores e com a Jerónimo Martins não acontece diferente

Ao findar a análise empreendida neste artigo, cabe destacar que os textos da área empresarial, mais especificamente os referentes à Responsabilidade Corporativa, são um rico material de estudo e de trabalho, não só para os profissionais da Comunicação - aos quais cabem sua elaboração em padrões e em linguagem voltados aos mais variados públicos, permitindo que esses consigam entender o que está explicitado nas produções textuais - como igualmente para os de Letras - que possuem o compromisso e objeto de labuta a capacidade de pensar teorias as quais facilitem cada vez mais a produção e a recepção dos textos/discursos -, bem como para os administradores das empresas - para os quais fica a responsabilidade de compreender da melhor maneira o que se ler nos textos como os estudados aqui, visando, posteriormente, aprová-los, pois são esses profissionais que serão os responsáveis por qualquer documento publicado em suas gestões, inclusive o Relatório investigado aqui. Dessa maneira, saber como esses textos são elaboradas e como devem ser lidos, usando-se as "pistas" neles deixadas pelo enunciador, locutor e sujeito falante deve ser tarefa desses profissionais - tendo consciência do que está produzindo e tendo capacidade de ler este tipo de material - são as contribuições deixadas por este trabalho.

Salienta-se ainda que os sujeitos falantes responsáveis por esse tipo de Relatório em questão são geralmente comunicadores que escrevem e geram locutores e enunciadores que verbalizam o discurso da Administração, estando assim sob a égide da formação discursiva desse campo do saber e não o da sua área de atuação.

Por fim, alcançou-se o objetivo demarcado para esse estudo, o qual versa sobrea a observação da construção discursiva da imagem empresarial, que coincide com a do ethos organizacional, o qual termina por auxiliar na elaboração textual que explicita o discurso acerca da Responsabilidade Corporativa preconizada e colocada em prática pelos administradores, chegando-se a conclusão que essa entidade retórica e discursiva é peça imprescindível para se construir um discurso organizacional o qual verbalize a consciência das empresas de suas responsabilidades perante à sociedade e o meio ambiente, fatos esses que foram encontrados no capítulo estudado no Relatório de Responsabilidade Corporativa 2016 da Jerónimo Martins.

\section{NOTAS}

${ }^{1}$ Stakeholder é um termo que se refere às partes interessadas ou públicos que devem estar de acordo com a forma de fazer negócio executada pela empresa. O sucesso de qualquer empreendimento depende da participação dessas partes e, por isso, é necessário assegurar que suas expectativas e necessidades sejam conhecidas e consideradas pelos gestores. De modo geral, essas expectativas envolvem satisfação de necessidades, compensação financeira e comportamento ético. Cada indivíduo ou grupo desses representa um determinado tipo de interesse no processo. $O$ envolvimento de todos eses não maximiza 
obrigatoriamente o processo, mas permite achar um equilíbrio de forças e minimizar riscos e impactos negativos na execução do processo oraganizacional.

2Embora a literatura venha a sugerir diferenças teóricas entre o uso dos termos 'empresa', 'organização', 'instituição', companhia' e 'corporação'. Para efeitos de fluidez textual deste trabalho, esses são utilizados como sinônimos.

${ }^{3}$ A Jerónimo Martins é um grupo multinacional português de distribuição alimentar e retalho especializado, presente, hodiernamente, em Portugal, Polónia e Colômbia.

${ }^{4} \mathrm{O}$ primeiro setor é o público; o segundo, o da iniciativa privada; o terceiro, constituído de organizações sem fins lucrativos.

${ }^{5}$ Dependendo da corporação pesquisada, o Relatório em questão estudado neste artigo termina por adquirir outras denominações díspar a de Responsabilidade Corporativa. Dessa forma, igualmente são intitulados de: Anual ou de Sustentabilidade Empresarial. Esses dois termos são os mais utilizados em solo brasileiro, enquanto que, em Portugal, há uma preferência do uso pelo primeiro, como é o caso do documento publicado pela Jerónimo Martins.

${ }^{6} \mathrm{Na}$ época de Aristóteles, aquele quem detinha status era o orador, enquanto que o escriba (o qual escrevia os textos ditados pelos oradores) era uma profissão desprestigiada, realizada por pessoas sem importância social. Diante disso, a pesquisadora manterá apenas a menção ao orador, mas se entenda que, em dias atuais, seria o correspondente ao orador e ao escritor.

${ }^{7}$ A nossa abordagem é o título do capítulo 1 do Relatório de Responsabilidade Corporativa 2016 da Jerónimo Martins, encontrado nas páginas 4 a 6 , e o documento foi retirado de <https://www.jeronimomartins.com/ wp-content/uploads/files\%20to\%20download/RESP.\%20 CORPORATIVA/RELATORIOS\%20DE\%20 RESPONSABILIDADE/PT/relatorio-de-responsabilidade-corporativa-2016-pt.pdf>.

${ }^{8}$ Informações mais detalhadas acerca da FTSE Rusell podem ser retiradas em <http://www.ftserussell. com/>, enquanto sobre os seus índices estão disponíveis em <http://www.ftse.com/Indices/FTSE4Good_ Index_Series/index.jsp>.

\section{REFERÊNCIAS}

Almeida, A. L. C. (2009). Identidade, imagem e reputação organizacional. In: Kunch, M. M. K. (Org.) (2009). Comunicação Organizacional: linguagem, gestão e perspectivas. v. 2. São Paulo: Saraiva.

Andrade, M. C. de (2018). Imagem empresarial construída discursivamente pelo Grupo Jerónimo Martins a partir de suas ações de Responsabilidade Corporativa. In: Atas CIAIQ 2018. v. 3. Fortaleza: CIAIQ, pp.7-16.

Aristóteles ([V a.C.] 1998). Retórica. Tradução de M. Alexandre Júnior et al. Lisboa: Imprensa Nacional/ Casa da Moeda.

Benveniste, É. (1995). Problemas de linguística geral I. 4. ed. Tradução de M. G. Novak e M. L. Neri. Campinas, SP: Pontes. 
Benveniste, É. (1989). Problemas de linguística geral II. Tradução de E. Guimarães et al. Campinas, SP: Pontes. pp. 75-76.

Breton, P. (1999). A argumentação na comunicação. Tradução de V. Ribeiro. Bauru, SP: EDUSC.

Dantas, E. B. Imagem organizacional e imagem de marca. In: Félix, J. B., \& Borda, G. Z. (Orgs.) (2009). Gestão da Comunicação e Responsabilidade Socioambiental: uma nova visão de Marketing e Comunicação para o desenvolvimento sustentável. São Paulo: Atlas. pp. 51-94.

Duarte, S. O. (2008). Informação S/A: o valor da comunicação para companhias abertas e para investidores. São Paulo: Saraiva.

Ducrot, O. O dizer e o dito (1987). Revisão técnica e tradução de E. Guimarães. Campinas, SP: Pontes.

Fiorin, J. L. (2002). As astúcias da enunciação: as categorias de pessoa, espaço e tempo. 2. ed. São Paulo: Ática.

Jerónimo Martins (2016). Relatório de Responsabilidade Corporativa 2016. Retrieved 12 January, 2018, from https://www.jeronimomartins.com/wp-content/uploads/files\%20\%20download/ resp.\%20corporativa/relatorios\%20de\%20responsabilidade/pt/relatorio-de-responsabilidadecorporativa-2016-pt.pdf

Kerbrat-Orecchioni, C. (1993). La enunciación: de la subjetividade en el language. 2. ed. Tradução de G. Ânfora e E. Gregores. Buenos Aires: Edicial.

Machado Filho, C. A. P. \& Zylbersztajn, D. (2004). Capital reputacional e responsabilidade social: considerações teóricas. Caderno de Pesquisas em Administração. São Paulo, v. 11, n. 2, pp. 8798, abril/jun.

Machado Filho, C. A. P. (2002). Responsabilidade social corporativa e a criação de valor para as organizações: um estudo multicasos. 204 f. Tese (Doutorado) - Faculdade de Economia, Administração e Contabilidade da Universidade de São Paulo. São Paulo: FEA/USP.

Meyer, M., Carrilho, M. M., \& Timmermans, B. (2002). História da Retórica. Lisboa: Temas e Debates.

Mussalim, F. (2001). Análise do discurso. In: Mussalim, F.; Bentes, A. C. (Org.) (2001). Introdução à lingüística: domínio e fronteira. v. 2. São Paulo: Cortez. pp. 101-142.

Naves, R. Responsabilidade social, sustentabilidade e governança corporativa em um contexto ético. In: Kunsch, M. M. K., \& Oliveira, I. L. (Orgs.) (2009). A comunicação na gestão da sustentabilidade das organizações. São Caetano do Sul, SP: Difusão. pp. 197-209. (Série Pensamento e Prática, 2).

Oliveira, J. A. P. de. Uma avaliação dos balanços sociais das 500 maiores. RAE-eletrônica, 4 (1), 1-19.

Orlandi, E. P. (2002). Análise do discurso: princípios e procedimentos. 4. ed. Campinas, SP: Pontes.

Perelman, C., \& Olbrechts-Tyteca, L. (2002). Tratado da argumentação: a nova retórica. Tradução de M. E. G. G. Pereira. São Paulo: Martins Fontes.

Ruão, T. (2003). As marcas e o valor da imagem: a dimensão simbolica das actividades ecónomicas. Caleidoscópio, 177-191.

Ruão, T. (2006). Marcas e Identidades. Porto: Campo de Letras. 
Sardinha, G. (2009). Sustentabilidade nas organizações. In Félix, J. B., \& Borda, G. Z. (Orgs.) (2009). Gestão da Comunicação e Responsabilidade Socioambiental: uma nova visão de Marketing e Comunicação para o desenvolvimento sustentável. São Paulo: Atlas. pp. 37-50.

Travassos, J. A. (2012). Responsabilidade Corporativa: institucionalização e ideologia. 2012. 93 f. Dissertação (Mestrado em Ciências Sociais) - Universidade Federal de Minas Gerais, Belo Horizonte.

Villafañe, J. (1998). Imagem Positiva. Lisboa: Edições Silabo. 